Research Article

\title{
Design Elements and Electrical Performance of a Bifacial BIPV Module
}

\author{
Jun-Gu Kang, ${ }^{1}$ Jin-Hee Kim, ${ }^{2}$ and Jun-Tae Kim ${ }^{3}$ \\ ${ }^{1}$ Graduate School, Department of Architectural Engineering, Kongju National University, 1223-24 Cheonandaero Seobuk-gu, \\ Cheonan-si, Chungnam 31080, Republic of Korea \\ ${ }^{2}$ Green Energy Technology Research Center, Kongju National University, 1223-24 Cheonandaero Seobuk-gu, Cheonan-si, \\ Chungnam 31080, Republic of Korea \\ ${ }^{3}$ Department of Architectural Engineering, Kongju National University, 1223-24 Cheonandaero Seobuk-gu, Cheonan-si, \\ Chungnam 31080, Republic of Korea
}

Correspondence should be addressed to Jun-Tae Kim; jtkim@kongju.ac.kr

Received 13 May 2016; Revised 11 August 2016; Accepted 31 August 2016

Academic Editor: Yanfa Yan

Copyright (C) 2016 Jun-Gu Kang et al. This is an open access article distributed under the Creative Commons Attribution License, which permits unrestricted use, distribution, and reproduction in any medium, provided the original work is properly cited.

Bifacial BIPV systems have great potential when applied to buildings given their use of a glass-to-glass structure. However, the performance of bifacial solar cells depends on a variety of design factors. Therefore, in order to apply bifacial solar cells to buildings, a bifacial PV module performance analysis should be carried out, including consideration of the various design elements and reflecting a wide range of installation conditions. This study focuses on the performance of a bifacial BIPV module applied to a building envelope. The results here show that the design elements of reflectivity and the transparent space ratio have the greatest impact on performance levels. The distance between the module and the wall had less of an impact on performance. The bifacial BIPV module produced output up to $30 \%$ greater than the output of monofacial PV modules, depending on the design elements. Bifacial BIPV modules themselves should have transparent space ratios of at least $30 \%$. When a dark color is used on the external wall with reflectivity of $50 \%$ or less, bifacial BIPV modules with transparent space ratios of $40 \%$ and above should be used. In order to achieve higher performance through the installation of bifacial BIPV modules, design conditions which facilitate reflectivity exceeding $50 \%$ and a transparent space ratio which exceeds $30 \%$ must be met.

\section{Introduction}

1.1. Background. Significant effort has been expended in the photovoltaic industry to develop highly efficient solar cells capable of producing higher output levels from smaller surfaces. The most widely used materials for highly efficient crystalline solar cells include those known as the "interdigitated back contact" and the "heterojunction with intrinsic thin-film." However, these highly efficient solar cells can cost at least $40 \%$ more than conventional crystalline silicon solar cells [1]. Therefore, interest is growing in alternative high efficiency solar cells, especially selective emitter solar cells, metallization wrap through solar cells, and bifacial solar cells, all of which are based on Si and offer high efficiency at low to moderate cost levels. Among these, bifacial solar cells, which can be produced using existing PV module manufacturing equipment, are capable of efficiently generating power from both the front and rear face. In addition, glass-to-glass bifacial solar cells can serve as a replacement for existing glass-toglass BIPV modules.

However, the performance of bifacial solar cells depends on a variety of factors, ranging from the characteristics of the back surface to the surrounding conditions. A range of studies have been carried out in an effort to understand the performance characteristics of bifacial PV modules installed outdoors, based on the installation factors. One such study was conducted by Chambouleyron and Chevalier, who attempted to enhance the performance of bifacial solar cells using mirrored or white surface reflectors [2]. Krenzinger and Lorenzo analyzed the annual generating performance of bifacial PV modules depending on the composition of the reflectors. They found that the reflector composition 
could enhance the performance by $10 \%-20 \%$ compared to the performance levels offered by monofacial PV modules [3]. Ooshaksaraei et al. investigated the impact of the installation conditions on bifacial PV module performance levels. Their experimental model consisted of four five-inch single-crystal bifacial silicone solar cells in a $2 \times 2$ formation with a transparent space ratio of $31 \%$. The results with these cells showed that the design elements had an effect on the power generation properties. The maximum level of generation was achieved when the distance between the bifacial solar cell and the reflector was $115 \mathrm{~mm}$. With regard to the reflector type, a semimirror reflector resulted in $20 \%$ more power being generated, while the diffuse reflector added contributed to $15 \%$ more generation than that of the front side of the PV module. Regarding the incident angle of the solar rays radiated on the bifacial PV module surface, maximum generation was achieved at $10^{\circ}$ [4]. Edmonds proposed a design which used a cylindrical reflector to increase the amount of power generated in bifacial modules by $27 \%$ [5]. Duran et al. analyzed the amount of power generated according to the color and reflectivity of the back reflector. Their experiment was conducted on south-facing bifacial solar cells installed at an incline of $30^{\circ}$, with the results showing performance enhancements of $7.5 \%$ and $21.4 \%$ when installed on grass, as in the green stuff on lawns and on a $90 \%$ reflective surface, respectively. An analysis of the electrical current in bifacial solar cells depending on the rear face color showed a $3.2 \%$ enhancement for black, a 5.0\% enhancement for beige, and a 7.9\% enhancement for white [6].

Bifacial solar cells can also be applied to BIPV modules. However, this requires the panels to be installed at a certain distance from the rooftop and with integrated reflectors to ensure solar radiation on the rear face. Moehlecke et al. proposed a bifacial solar cell panel with integrated reflectors for installation onto a building envelope. This panel was shown to generate $35 \%$ more electricity per year compared to a panel with monofacial solar cells with the same surface area [7]. Silveira et al. proposed the use of strings of pseudo-square bifacial cells, instead of the round cells of the first prototypes presented by Moehlecke and Krenzinger [8].

Hezel [9] proposed a bifacial PV module which can be applied to shades on buildings. The bifacial PV module is applied at an angle of 45 degrees from the window as a shading device with a semitransparent reflector material. Solar radiation passes the transparent space of the bifacial PV module and is then rereflected by the semitransparent reflector at the backside of the bifacial PV. The proposed bifacial PV module was composed of $100 \mathrm{~mm} \times 100 \mathrm{~mm}$ cells in a $4 \times 10$ formation with a transparent space ratio of $50 \%$. Experimental results showed that this bifacial PV module achieved an enhancement of more than $37 \%$ in terms of the generating performance compared to that achieved by ordinary monofacial PV modules.

This review of the existing literature shows that the performance capabilities of bifacial solar cells are affected by the rear face conditions and by certain environmental variables, making it difficult to propose a quantitative standard for generation performance. Moreover, as bifacial solar cells are relatively new to the photovoltaic industry, no standard methodology exists which can be used to analyze their performance capabilities. Currently, the performance capabilities of bifacial solar cell are tested on both the front and rear faces in standard testing conditions (STC). Using this approach makes it difficult to obtain quantitative measures of bifacial PV module performance levels depending on the installation conditions.

Therefore, in order to apply bifacial solar cells to buildings, a bifacial PV module performance analysis should be carried out while taking into account various design elements and reflecting a wide range of installation conditions.

This study was conducted to analyze the relationship between photovoltaic performance levels and the design elements that should be considered when applying bifacial silicon PV modules to buildings. To conduct this investigation, modules were fabricated with design elements associated with bifacial silicone PV modules and were then tested under identical conditions using a solar simulator. The measured power outputs by each type of BIPV modules were then assessed in a statistical analysis to determine the relationship between the electrical performance capabilities of the bifacial BIPV modules and their design elements.

\section{Design Elements of Bifacial BIPV Modules}

The performance of the bifacial BIPV module is affected by installation factors such as the distance between the PV module and the inner wall and by the reflective properties of the inner wall. It is also affected by module design elements such as the solar cell formation method used and the transparent space ratio. To evaluate the effects of various elements, it is necessary to select the elements which have a relatively high impact. Identifying such elements can be accomplished through an analysis of variance (ANOVA). Therefore, the ANOVA approach was used to identify the impact of the respective design elements on the bifacial BIPV module performance capabilities. Moreover, with the key design elements derived through the ANOVA as independent variables and the performance levels of the bifacial BIPV module as the dependent variable, a multiple regression analysis was carried out to analyze the performance of the bifacial BIPV module.

2.1. Analysis of the Design Elements. Through the literature review, this study identified three design elements which have an effect on the bifacial PV performance levels. These are shown in Figure 1.

The first was the transparent space ratio, as determined by the space between the cells. The maximum transparent space ratio was set to $50 \%$ considering the surface area output of the PV module; hence, the transparent space was not larger than the cell surface area. Five different transparent space ratios of $10 \%, 20 \%, 30 \%, 40 \%$, and $50 \%$ were selected. Additionally, two types of cell placements were selected: grid and line types.

The second design element was the reflectivity of the wall on which the bifacial PV module was installed. Usually, the inner surfaces of exterior walls on buildings are clad with waterproof sheets or reflective insulation, as shown in Figure 2. 


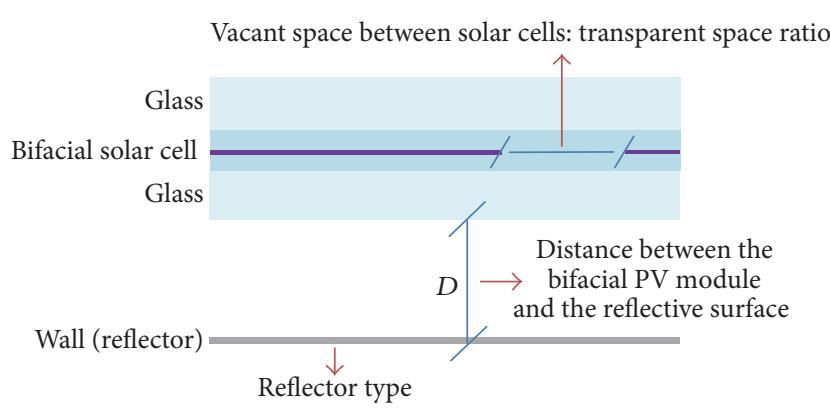

FIGURE 1: Key parameters affecting the bifacial PV performance.

TABLE 1: Design elements for the bifacial BIPV module.

\begin{tabular}{lccccc}
\hline Design elements & \multicolumn{5}{c}{ Level } \\
& 1 & 2 & 3 & 4 & 5 \\
\hline $\begin{array}{l}\text { Module design } \\
T(\%)\end{array}$ & 10 & 20 & 30 & 40 & 50 \\
$\begin{array}{l}M \text {-type } \\
\text { Installation conditions }\end{array}$ & Grid type & Line type & & & \\
$D(\mathrm{~mm})$ & 30 & 60 & 120 & 180 & 240 \\
$R(\%)$ & 5 & 47 & 72 & 82 & \\
$R$-type & Diffuse type & Mirror type \\
\hline
\end{tabular}

$T$ : transparent space, $D$ : distance, $R$ : reflectivity, $M$-type: module setting type, and $R$-type: reflector type.

The spandrels in curtain walls are usually installed with finishing materials such as aluminum composite panels or stone, with insulation panels inside. If BIPV modules are used as building envelopes, the inner wall surface can be covered with a variety of reflective materials, the selection of which has a significant impact on the performance capabilities of bifacial PV modules. The experimental variables of a black reflector, a white reflector, a red reflector, and an aluminum reflector were selected for this design element. The aluminum reflector was further classified into two types based on the surface properties: mirror reflection and diffuse reflection.

The reflectivity was measured using a Shimadzu UV3600 spectrometer. Accounting for the spectrum response characteristics of the bifacial cell, the average reflectivity in the wavelength range of $300 \mathrm{~nm} \sim 1200 \mathrm{~nm}$ was utilized as the reflectivity measurement. As shown in Figure 3, the reflectivity levels of the black, red, white, and aluminum reflectors used were $5 \%, 47 \%, 72 \%$, and $82 \%$ respectively.

The third design element was the distance between the bifacial PV module and the reflective surface (inner wall). Experimental distances were selected by considering the curtain wall frame thickness and insulation panel thickness in the curtain wall systems, where BIPV modules are typically installed. The five distances selected were $30,60,120,180$, and $240 \mathrm{~mm}$ between the PV module and the reflector. The three bifacial BIPV module design elements that were applied in this study are outlined in Table 1.

The design elements and levels thus resulted in a total of 400 experimental cases. Factor screening was then carried out using the experimental design to select the experimental cases.

2.2. Selection of Experimental Cases according to the Experimental Design. The statistics software Minitab 17 was used to create combinations of design elements according to the experimental design. The order of the experiments was randomized to minimize the impact of factors other than the experimental variables.

Experimental cases were placed in three stages according to the design elements. The first stage of the experimental cases used a factorial design, resulting in the establishment of 27 experimental cases. Variance in the levels of the design elements with regard to the transparent space ratios and distances was controlled by eliminating the minimum and maximum values from the selected design elements. As a result, the corresponding ranges of $20 \%$ to $40 \%$ and $60 \mathrm{~mm}$ to $180 \mathrm{~mm}$ were selected. Regarding the reflectivity, the aluminum reflectors were eliminated, leaving only black, red, and white.

The second stage of the experimental cases involved cell placement. Two cell placement types, grid and line types, were selected. For each type, five levels of transparent space ranging from $10 \%$ to $50 \%$ were selected, with modulereflector distances ranging from $60 \mathrm{~mm}$ to $120 \mathrm{~mm}$, generating a total of 20 experimental cases.

The third stage of the experimental cases was designed to test the photovoltaic performance depending on mirror reflection or diffuse reflection using aluminum reflectors with identical levels of reflectivity. All five design element levels of the transparent space ratio $(10 \%, 20 \%, 30 \%$, and $50 \%)$ and the module-reflector distance $(30,60,120$, and $240 \mathrm{~mm})$ were selected, and an orthogonal array was used to create 16 experimental cases.

\section{Bifacial BIPV Performance Testing}

3.1. Specimen Design and Fabrication. The bifacial PV modules were fabricated using bifacial solar cells from manufacturer P, based in Japan. Surface electrodes were designed in the three busbar layout, similar to that used with monofacial crystalline silicone solar cells.

The front and rear faces were nearly identical in terms of appearance. The average efficiency levels of the bifacial cells used in this study are as outlined in Table 2: 19.4\% in the front and $19.1 \%$ in the rear. The performance of the bifacial PV is presented as the front-rear maximum output ratio at the Standard Test Condition (STC), and the bifacial $\mathrm{PV}$ used in this study had a front-rear maximum output ratio of $98.5 \%$ with the rear face performance similar to the front face performance.

Ten types of bifacial PV modules were produced using 16 cells each in $4 \times 4$ layouts with different transparent space ratios and cell placements, as shown in Figure 4.

To ensure radiation transmission onto the rear face, a transparent back sheet was used in the modules, as shown in Figure 5. In order to test the bifacial BIPV performance according to the design elements, a test box was made, as shown in Figure 6. The test box was $109 \mathrm{~mm} \times 1430 \mathrm{~mm} \times$ 

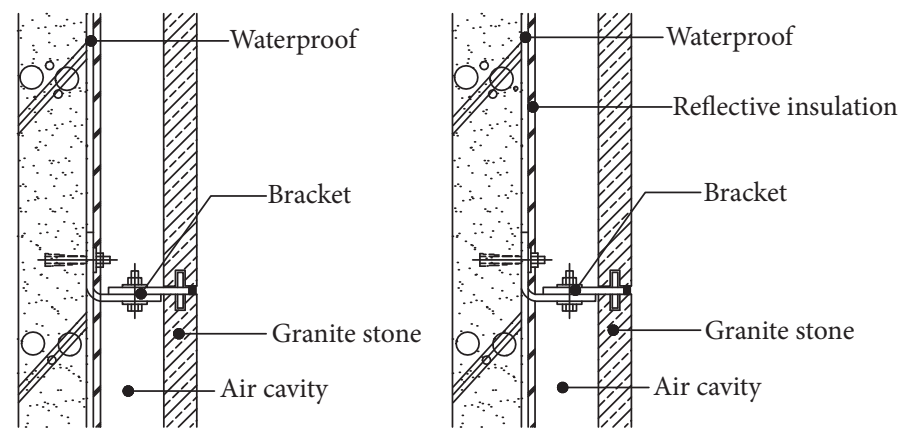

FIGURE 2: Wall section detail.

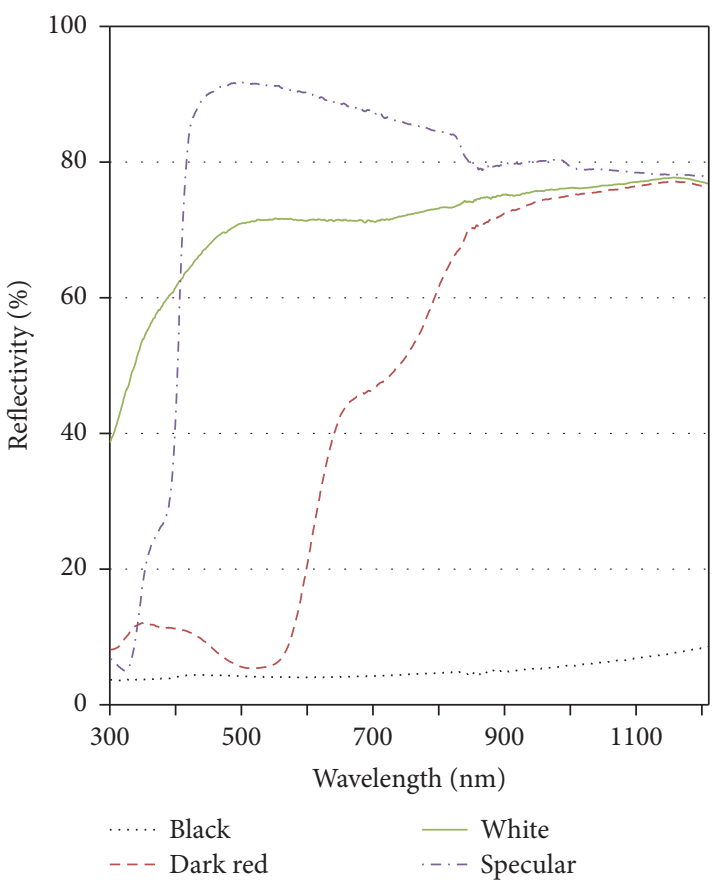

FIGURE 3: Reflectivity by reflector type.

TABLE 2: Rated electrical specifications of the bifacial cell.

\begin{tabular}{lccc}
\hline & Front & Rear & Bifacial \\
\hline Efficiency (\%) & 19.4 & 19.1 & \\
$P_{\max }(\mathrm{W})$ & 4.63 & 4.56 & $98.5 \%$ \\
$V_{\mathrm{oc}}(\mathrm{V})$ & 0.646 & 0.646 & \\
$I_{\mathrm{sc}}(\mathrm{A})$ & 9.08 & 8.96 & \\
$V_{\mathrm{pm}}(\mathrm{V})$ & 0.550 & 0.547 & \\
$I_{\mathrm{mp}}(\mathrm{A})$ & 8.42 & 8.34 & \\
\hline
\end{tabular}

$P_{\text {max }}$ : maximum power, $V_{\mathrm{pm}}$ : voltage at $P_{\max }, I_{\mathrm{mp}}:$ current at $P_{\max }, V_{\mathrm{oc}}$ : opencircuit voltage, and $I_{\mathrm{sc}}$ : short-circuit current.

$500 \mathrm{~mm}$ in size, with black finishing on the inside to minimize the effect of reflectivity.

The ten types of bifacial BIPV modules of various sizes were inserted into panel frames, and panels $990 \mathrm{~mm} \times$ $1330 \mathrm{~mm}$ in size were placed in front of the test box, as shown in Figure 7. The reflectors were inserted behind the test box, and the sliders allowed them to be moved closer to or farther from the panels on the front.

3.2. Methodology and Equipment. The performance of the front and rear faces of the bifacial PV modules wase tested separately, as no standard methodology exists for measuring the performance of both faces simultaneously.

The performance of the PV modules is presented as the rated specifications tested under STC. Therefore, the standard test conditions (radiation strength $1000 \mathrm{~W} / \mathrm{m}^{2}$, module temperature $25^{\circ} \mathrm{C}$ ) were used to measure the performance of the bifacial BIPV modules with an integrated reflector. A Pasan sun simulator test room was used to conduct these tests. This is a highly reliable IEC class A piece of equipment with an electronic-load precision level of $\pm 0.5 \%$ [10].

The experiment was carried out as shown in Figure 8 by installing the bifacial BIPV modules vertically on the support with an irradiation distance of $4 \mathrm{~m}$ and an irradiation magnitude of $1000 \mathrm{~W} / \mathrm{m}^{2}$, according to the order of the selected experiment cases. Figure 9 shows an image of the experimental setting, depicting the flash unit and the bifacial BIPV module in the sun simulator test room.

\section{Results and Analysis}

The power generation performance of the bifacial BIPV is influenced in diverse and complex ways by the design elements. Among the various design elements which can be used, those that have a direct influence on the power generation performance must be selected for a proper analysis. Important design elements can be selected through an analysis of variance (ANOVA), a statistical method used to select significant variables by examining the relationship between a dependent variable (power generation of bifacial BIPV modules) and one or more independent variables (design elements) [11]. Based on the results of an ANOVA, the contribution and effects of design elements on the power generation performance of bifacial modules were assessed. A multifactor ANOVA was employed in order to analyze the interactions between the design elements and the different dependent variables (results). The resulting regression equation revealed the relative importance of the design elements and provided estimates of the bifacial BIPV performance. The average power generation of the bifacial BIPV modules 

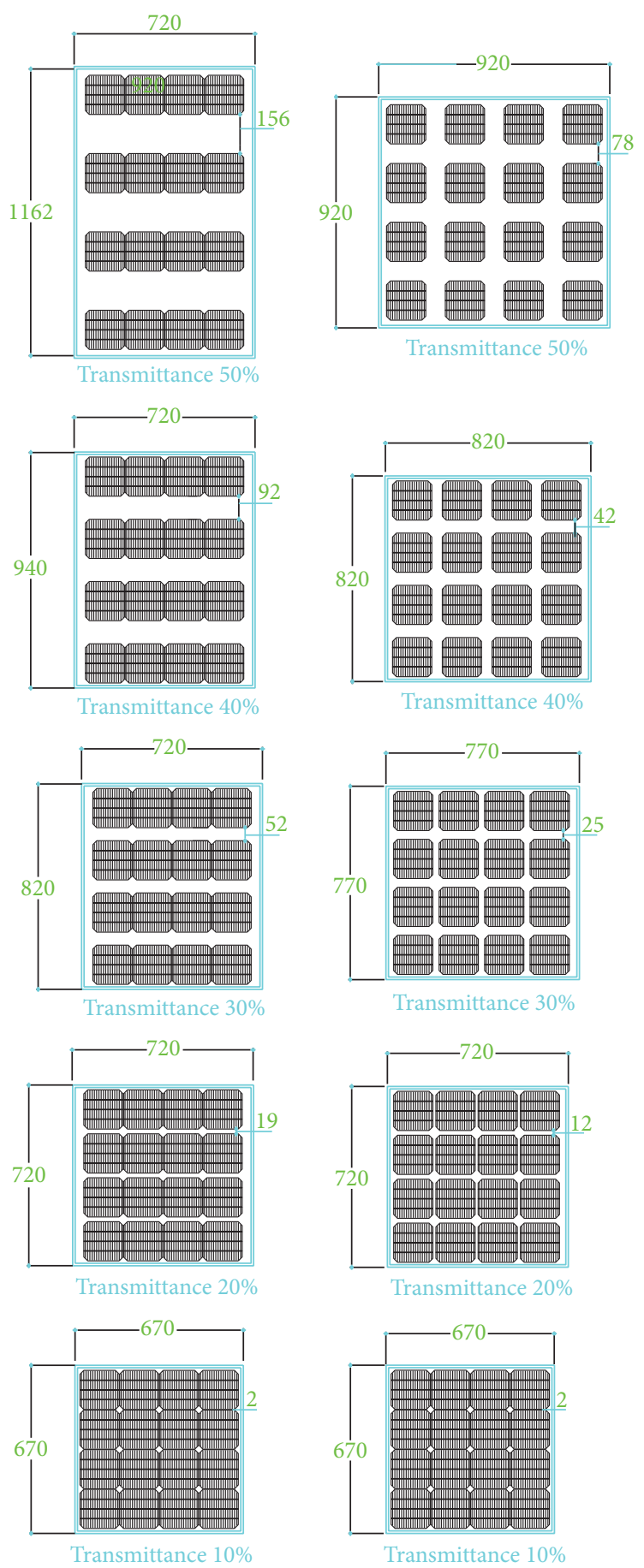

(a) Line type

(b) Grid type

FIgURE 4: Module types according to the cell placement method used.

was obtained according to the design elements for each experiment type before performing the ANOVA.

To analyze the power generation performance of the bifacial modules in relation to transmissivity, the power generation of the front modules was measured with opaque sheets attached on the back and vice versa. The power generation levels of the front and back modules were found to be $54.2 \mathrm{~W}$ and $54.1 \mathrm{~W}$, respectively.
4.1. Analysis of Variance (ANOVA). The analysis of variance (ANOVA) showed that the transparent space ratio, inner wall reflectivity, module-to-inner wall distance, and the combination of the transparent space ratio and reflectivity were significant, at a significance level of 0.05 . On the other hand, the combinations of the transparent space ratio and distance as well as the reflectivity and distance had $P$ values of 0.409 and 0.920 , respectively, and thus were not significant. 


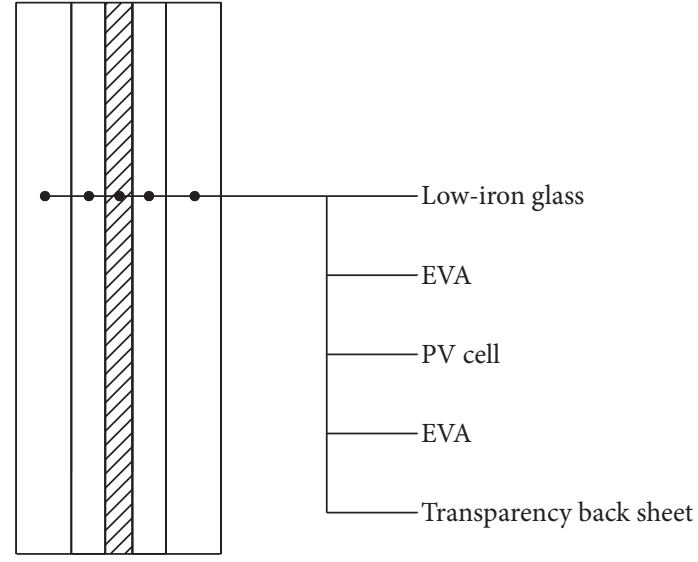

FIGURE 5: Schematic sketch (not to scale) showing the bifacial PV module configuration.

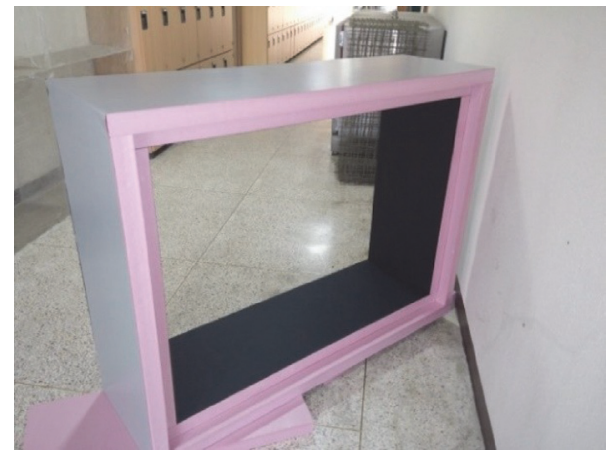

Figure 6: Test box configuration for the indoor bifacial BIPV panel with an integrated reflector.

TABle 3: Analysis of variance.

\begin{tabular}{lccccc}
\hline Source & DF & SS & MS & $P$ value & $\rho$ \\
\hline$T(\%)$ & 2 & 87.961 & 43.980 & 0.000 & $17.89 \%$ \\
$R(\%)$ & 2 & 366.708 & 183.354 & 0.000 & $74.57 \%$ \\
$D(\mathrm{~mm})$ & 2 & 11.296 & 5.648 & 0.000 & $2.30 \%$ \\
$T \& R$ & 4 & 19.659 & 4.915 & 0.000 & $4.00 \%$ \\
Error & 16 & 6.135 & 0.383 & & $1.25 \%$ \\
Total & 26 & 491.759 & & & $100 \%$ \\
\hline
\end{tabular}

$T$ (\%): transparent space ratio, $R(\%)$ : reflectivity, $D(\mathrm{~mm})$ : distance between module and inner wall, DF: Degrees of Freedom, SS: sum of square, MS: Mean Square, $P$ value: significant probability, and $\rho$ : contribution ratio.

The ANOVA table is presented as Table 3. In addition, the respective contribution rates of the significant design elements were calculated according to formula (1) as the total variance of the treatment term divided by the total sum of squares.

$$
\rho(\%)=\frac{\mathrm{SS}_{x 1 \sim x 3}}{\mathrm{SS}_{y}} \times 100 .
$$

Among the design elements, the reflectivity made the greatest contribution to the photovoltaic performance, at $74.6 \%$. This was followed by the transparent space ratio, at
$17.89 \%$. In contrast, the combination of the transparent space ratio and reflectivity and the module-reflector distance only contributed $2.3 \sim 4 \%$, having significantly less impact than the reflectivity and transparent space ratio.

As shown in Figure 10, a larger transparent space ratio and reflectivity value led to more enhanced photovoltaic performance. With regard to the module-reflector distance, the maximum photovoltaic performance was observed at $120 \mathrm{~mm}$, with the values declining from that point. This shows the importance of ensuring the appropriate distance between the module and the rear reflector to allow radiation to be transmitted to the rear. The performance change was most pronounced for changes in the reflectivity, whereas the change was smallest with changes in the module-reflector distance.

Figure 11 shows the effects of the interaction between the design elements. There is an interaction effect between changes in the reflectivity and transparent space ratio on the power generation, but the reflectivity has more of an effect than the transparent space. The power generation remained relatively constant for the transparent space and distance and for the reflectivity and distance, showing a minimal interaction effect. With reference to the impact of individual design elements on the performance, the transparent space ratio had a greater impact than the module-reflector distance, while the reflectivity had more of an impact than the modulereflector distance.

Looking at cell placement, power generation was similar for the line and grid types, as shown in Figure 12. The power generation level was also similar between the mirror reflection and the diffuse reflection types, as shown in Figure 13. Therefore, cell placement and reflectivity were shown to have minimal impact on the photovoltaic performance.

4.2. Multiple Regression Analysis. A multiple regression analysis was carried out for the design elements derived from the ANOVA in an effort to understand the photovoltaic properties of the bifacial BIPV module. Through the multiple regression analysis, the performance of the bifacial BIPV module was derived using

$$
\begin{aligned}
\operatorname{BiPower}(\mathrm{W})= & 54.012+0.1011 \times T+0.05783 \times R \\
& -0.00795 \times D+0.002581 \times T \times R,
\end{aligned}
$$

where BiPower (W) is Bifacial BIPV output, $T$ (\%) is transparent space ratio, $R(\%)$ is reflectivity, and $D(\mathrm{~mm})$ is distance between the module and inner wall.

The multiple regression equation can be examined through the model summary presented in Table 4. S, representing the correlation between independent variables, was 0.372645 . This shows the correlation between the independent variables of the transparent space ratio, reflectivity, module-reflector distance, and the combination of the transparent space ratio and reflectivity, confirming the independent nature of the respective design elements. The coefficient of determination, $R^{2}$ (R-squared), was 0.9935 , showing that the independent variables (design elements) explained $99.35 \%$ of the dependent variable (performance). 

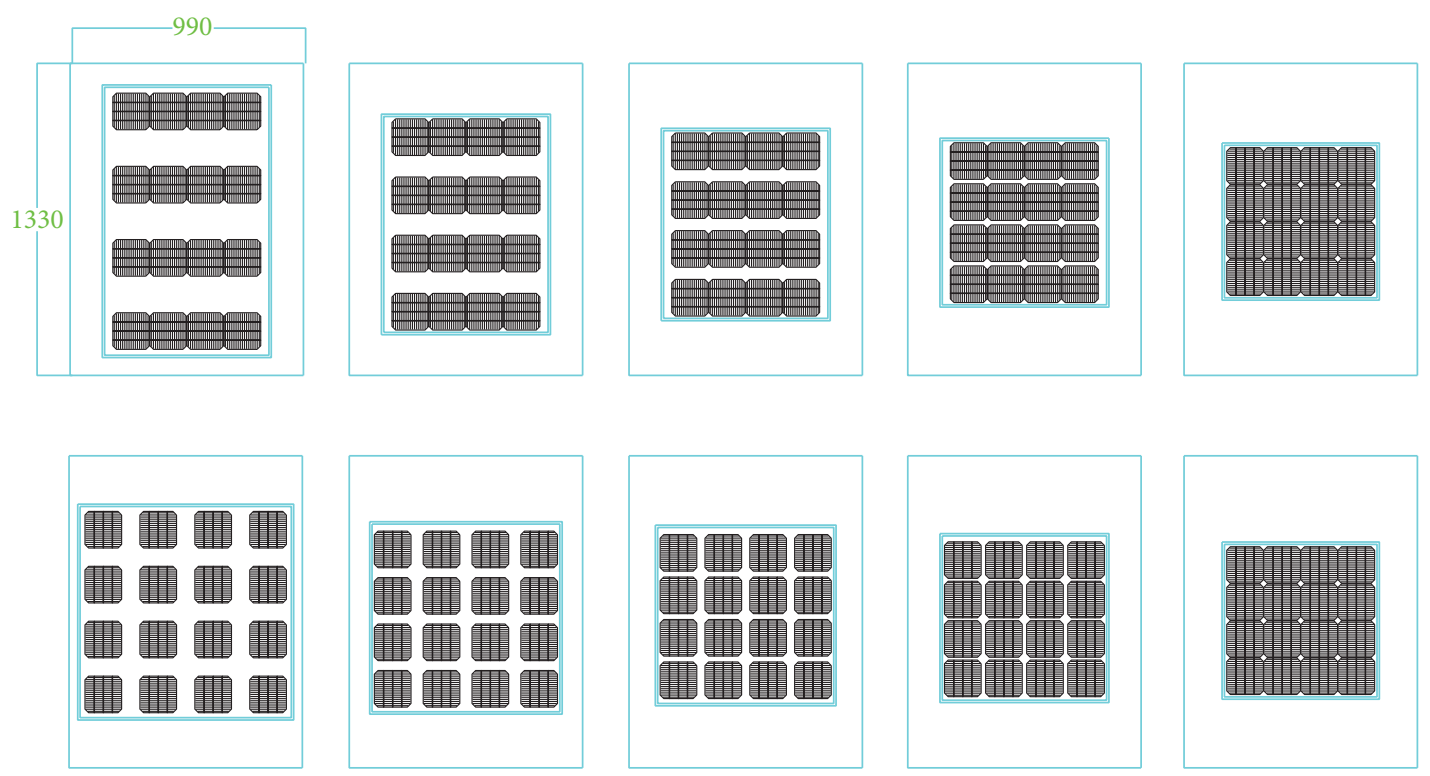

FIgURE 7: Bifacial BIPV panel with frames.

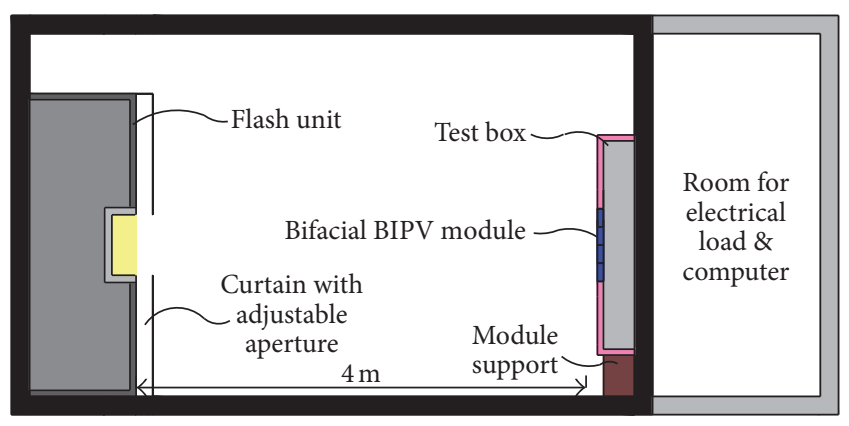

FIGURE 8: Conceptual view of the experimental set-up with the sun simulator test room.

TABLE 4: Model summary.

\begin{tabular}{lccc}
\hline$S$ & $R^{2}$ & $R^{2}$ (adj) & $R^{2}$ (pred) \\
\hline 0.372645 & 0.9935 & 0.9923 & 0.9903 \\
\hline
\end{tabular}

Therefore, the derived regression model is deemed to be appropriate.

The regression coefficients table (Table 5) shows the results of the statistical testing of the design elements. The derived regression equation was shown to be significant at the significance level of 0.05 in the significance level $P$ test. Therefore, the model for photovoltaic performance was shown to be appropriate.

The analysis of the bifacial BIPV module performance based on the multiple regression equation showed that the selected design conditions resulted in a maximum performance enhancement of $35.3 \%$ compared to existing modules. It also showed that the module-reflector distance had a minimal effect on the photovoltaic performance and that maximum performance was achieved at $120 \mathrm{~mm}$.
TABLE 5: Regression coefficients table.

\begin{tabular}{lcccc}
\hline Term & Coefficients & SE coefficients & $T$ value & $P$ value \\
\hline Constant & 54.012 & 0.522 & 103.53 & 0.000 \\
$D(\%)$ & 0.1011 & 0.0158 & 6.40 & 0.000 \\
$R(\%)$ & 0.05783 & 0.00988 & 5.85 & 0.000 \\
$D(\mathrm{~mm})$ & -0.00795 & 0.00146 & -5.43 & 0.000 \\
$T \& R$ & 0.002581 & 0.000318 & 8.12 & 0.000 \\
\hline
\end{tabular}

SE coefficients: standard error coefficients. $T$ value: the $T$ value is a test statistic for $t$-tests that measures the difference between an observed sample statistic and its hypothesized population parameter in units of standard error. $P$ value: significant probability.

\section{Conclusion}

This study used experiments to analyze the impact of design elements on the performance of a bifacial BIPV module for the application of bifacial PV modules onto the exterior walls of a building.

The analysis of variance showed that the design elements of the reflectivity and transparent space ratio had the greatest impact on the performance capabilities. The distance between the module and the wall had less of an impact on the performance. These results indicate the importance of selecting a highly reflective finishing material for exterior walls when applying bifacial PV modules to building envelopes. In the design of the bifacial BIPV modules, cell placements with higher transparent space ratios would be conducive to enhancing the power generation performance.

The bifacial BIPV module produced output up to $30 \%$ higher than that of the front face modules, depending on the design elements. Thus, the potential benefits of replacing existing monofacial BIPV modules with bifacial BIPV modules were confirmed. 


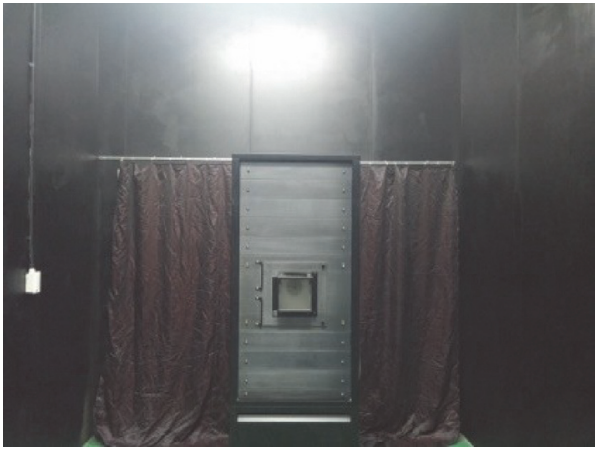

(a)

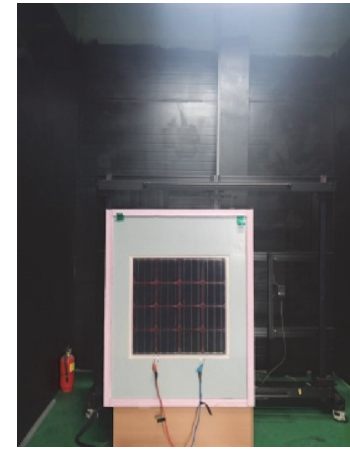

(b)

FIGURE 9: Photograph of the flash unit (a) and the bifacial BIPV module set-up (b) in the sun simulator test room.
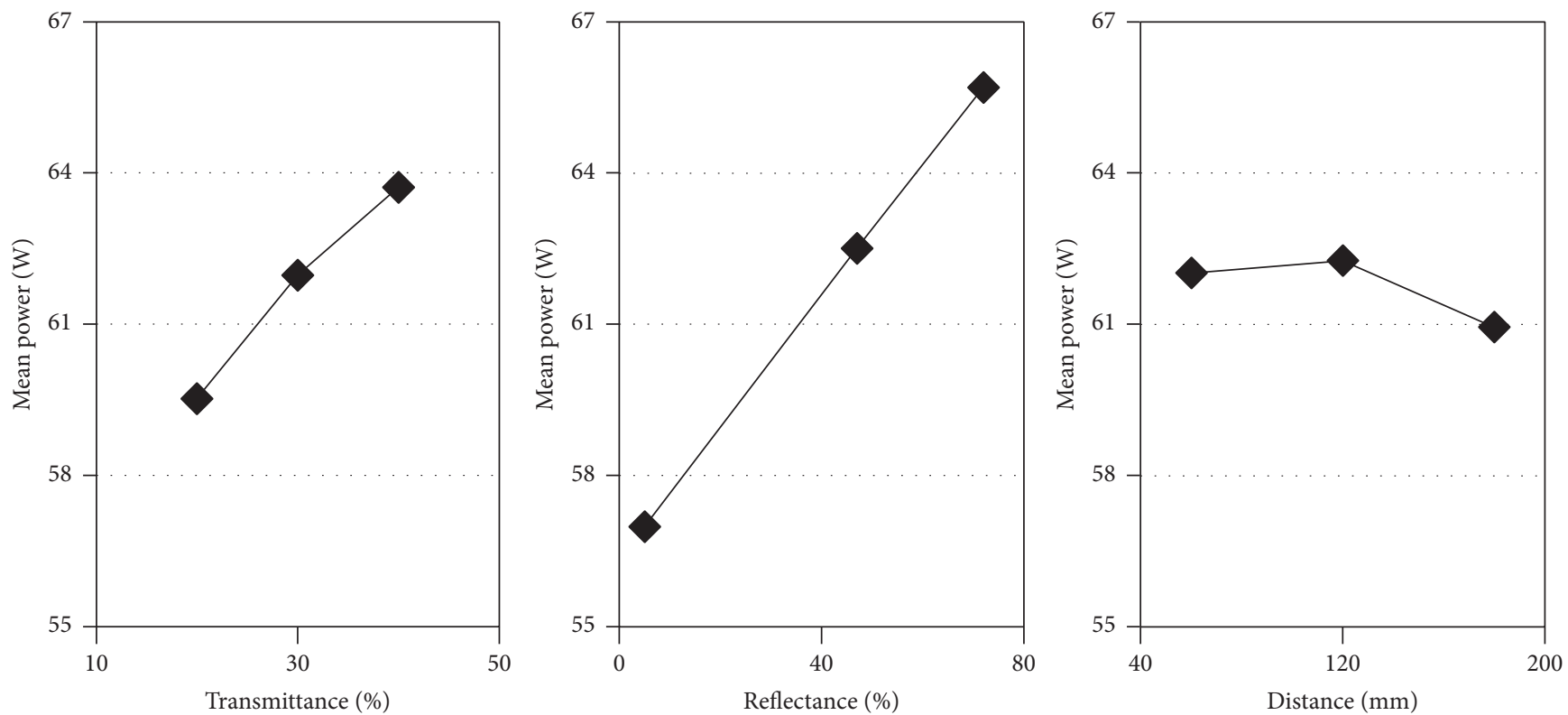

FIGURE 10: Main effect according to the design elements.
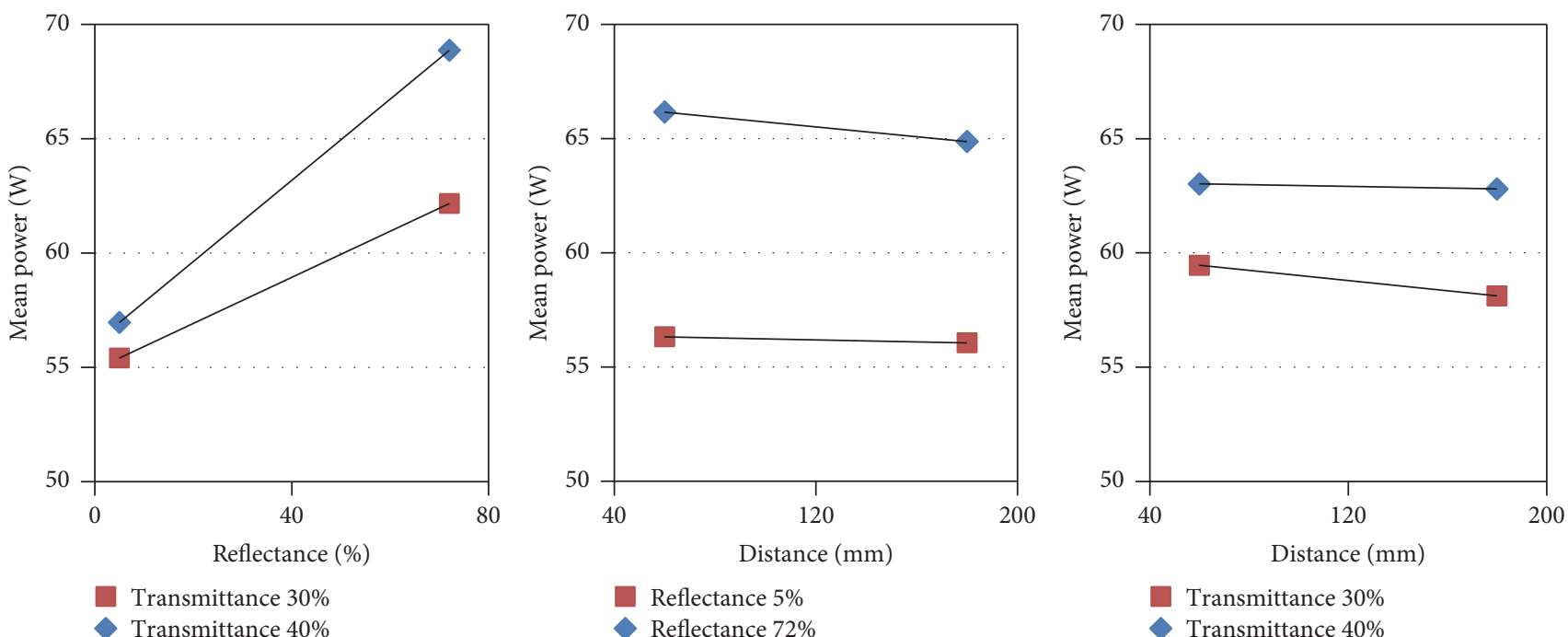

FIGURE 11: Interaction effect according to the design elements. 


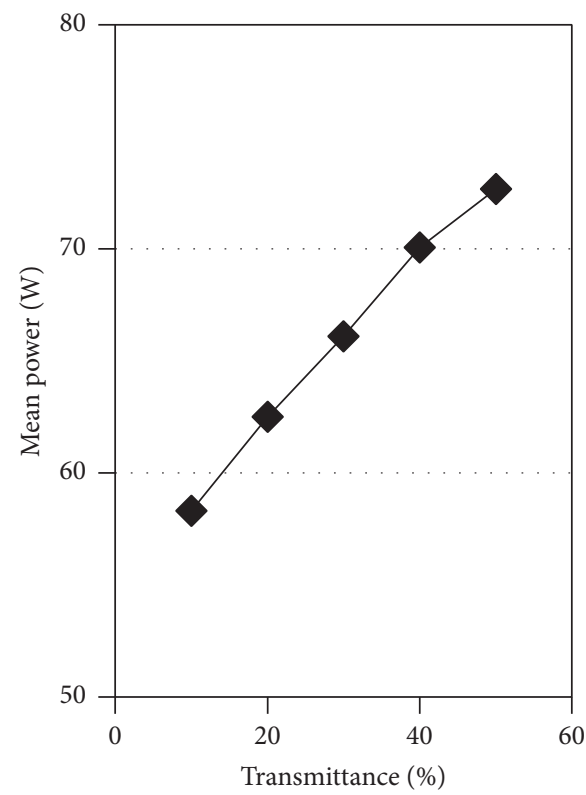

(a) Line type

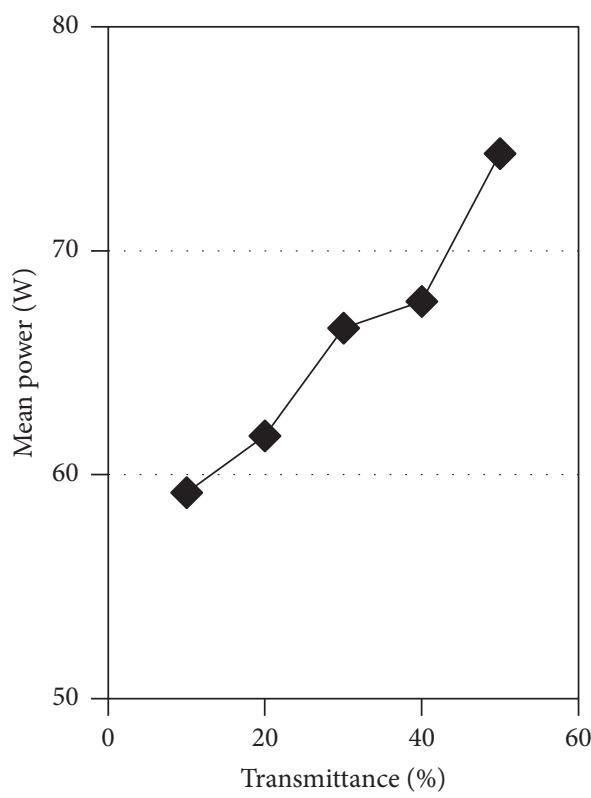

(b) Grid type

FIGURE 12: Electrical generation according to the module type.

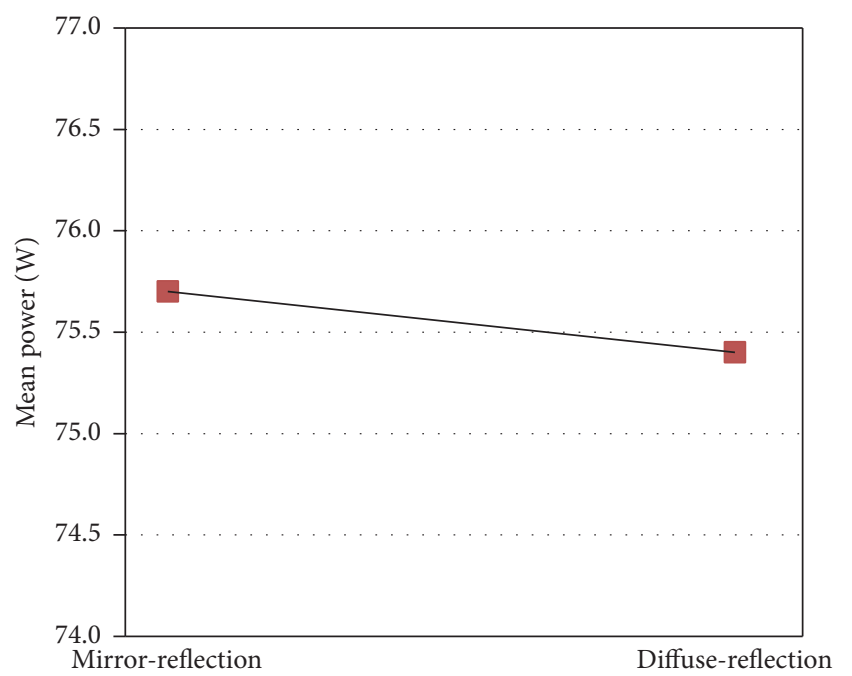

FIGURE 13: Electrical generation according to reflectivity.

A 20\% enhancement in the bifacial BIPV module performance could be achieved by modifying the reflectivity and transparent space ratio, which were shown to have a dominant impact on the performance in the regression equation. The external wall reflectivity was the most important variable during the installation of the bifacial BIPV module, and a bright color with reflectivity of at least $80 \%$ should be used.

The bifacial BIPV modules themselves should have transparent space ratios of at least 30\%. When a dark color is used on the external wall with reflectivity of $50 \%$ and below, bifacial BIPV modules with transparent space ratios of $40 \%$ at a minimum should be used. In order to achieve higher performance through the installation of bifacial BIPV modules, design conditions which include reflectivity exceeding 50\% and a transparent space ratio which exceeds $30 \%$ must be met. In addition, bifacial BIPV modules with suitable transparent space ratios must be used, depending on the properties of the exterior wall finishing material.

Given that this study provides a statistical analysis of limited design conditions under standard testing conditions, it is limited in its ability to establish bifacial BIPV module performance standards depending on outdoor installation conditions. Therefore, a follow-up study should be conducted with outdoor performance experiments considering additional design elements, such as the bifacial PV module temperature, incline angle, and orientation.

\section{Competing Interests}

The authors declare no conflict of interests.

\section{Acknowledgments}

This work was supported by the Korea Institute of Energy Technology Evaluation and Planning (KETEP) and by the Ministry of Trade, Industry \& Energy (MOTIE) of the Republic of Korea (no. 20134010200540 and no. 20143010011910).

\section{References}

[1] SNE Research, "The latest high-efficiency crystalline Si Solar Cell Technology and Market Forecast 2006-2015,” p. 28, 2013.

[2] I. Chambouleyron and Y. Chevalier, "Silicon double solar cell," in Proceedings of the European Photovoltaic Solar Energy Conference, pp. 967-976, September 1977.

[3] A. Krenzinger and E. Lorenzo, "Estimation of radiation incident on bifacial albedo-collecting panels," International Journal of Solar Energy, vol. 4, no. 5, pp. 297-319, 1986. 
[4] P. Ooshaksaraei, K. Sopian, R. Zulkifli, M. A. Alghoul, and S. H. Zaidi, "Characterization of a bifacial photovoltaic panel integrated with external diffuse and semimirror type reflectors," International Journal of Photoenergy, vol. 2013, Article ID 465837, 7 pages, 2013.

[5] I. R. Edmonds, "The performance of bifacial solar cells in static solar concentrators," Solar Energy Materials, vol. 21, no. 2-3, pp. 173-190, 1990.

[6] C. Duran, T. Buck, R. Kopecek, J. Libal, and F. Traverso, "Bifacial solar cells with boron back surface field," in Proceedings of the 25th European Photovoltaic Solar Energy Conference and Exhibition, 5th World Conference on Photovoltaic Energy Conversion, pp. 2348-2352, Valencia, Spain, September 2010.

[7] A. Moehlecke, F. S. Febras, and I. Zanesco, "Electrical performance analysis of PV modules with bifacial silicon solar cells and white diffuse reflector," Solar Energy, vol. 96, pp. 253-262, 2013.

[8] H. Silveira, I. Zanesco, and A. Moehlecke, "Optimization of the modified static plain concentrator module," in Proceedings of the 5th Latin-American Congress: Electricity Generation and Transmission, pp. 1-10, 2003.

[9] R. Hezel, "Novel applications of bifacial solar cells," Progress in Photovoltaics: Research and Applications, vol. 11, no. 8, pp. 549556, 2003.

[10] “Pasan Sun Simulator Operating Manual," Version 2.2d, 2006.

[11] N. Gyeong-Seop, Well Known Writing Papers Statistical Analysis SPSS \& AMOS 21, Hanbit Academy, Seoul, South Korea, 2014. 

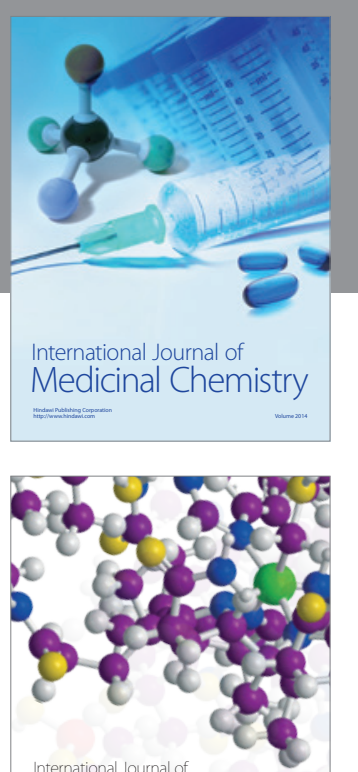

Carbohydrate Chemistry

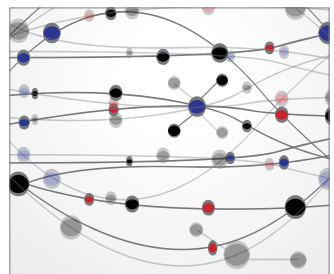

The Scientific World Journal
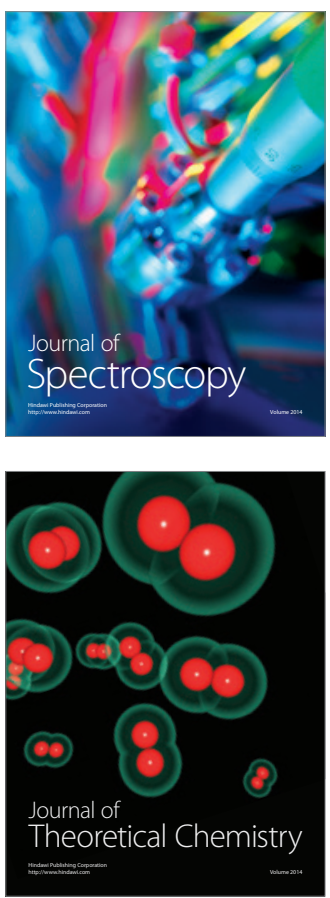
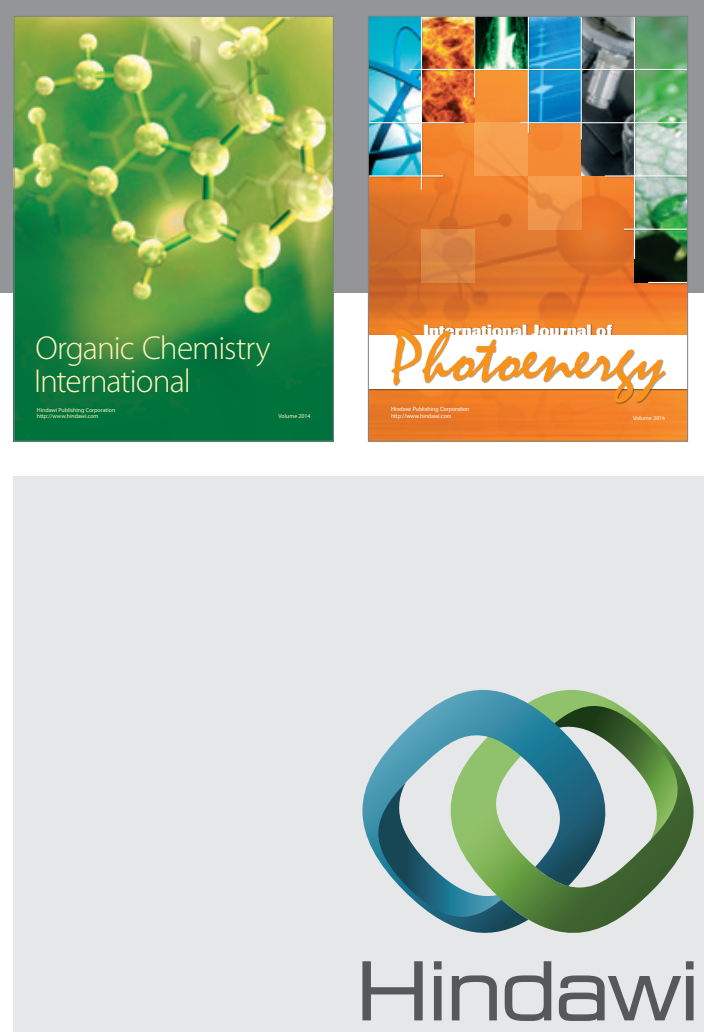

Submit your manuscripts at

http://www.hindawi.com

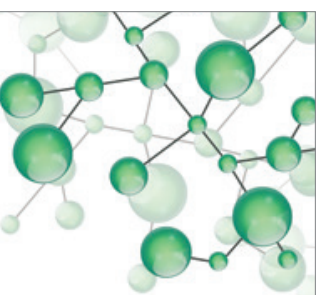

International Journal of

Inorganic Chemistry

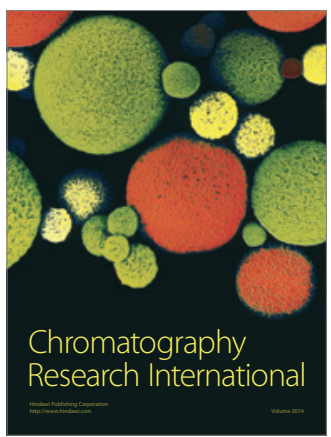

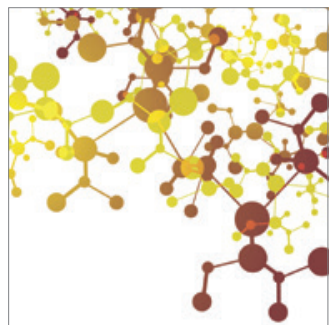

Applied Chemistry
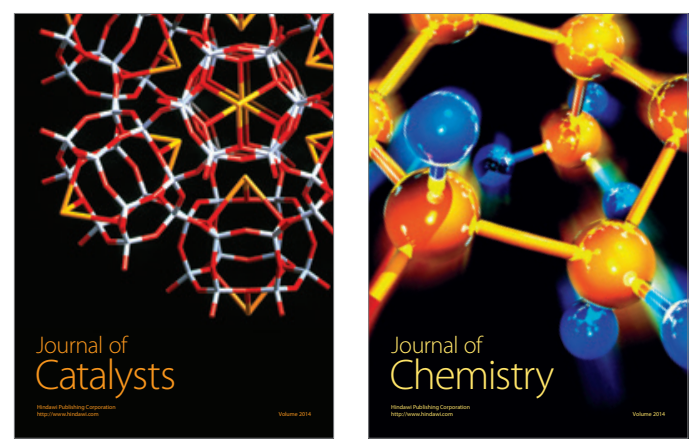
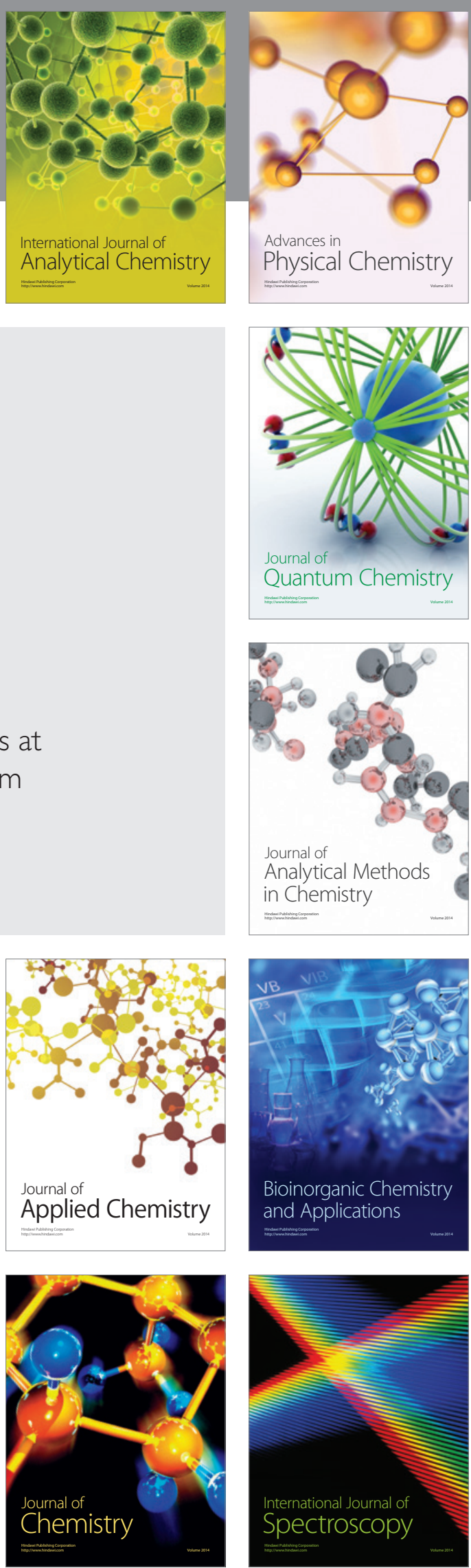